\title{
MODIFICAÇÃO DA CONCENTRAÇÃO DE AMIDO RESISTENTE EM FEIJÃO MACASSAR (Vigna unguiculata L. WALP) POR TRATAMENTO HIDROTÉRMICO E CONGELAMENTO
}

\author{
Silvana Magalhães SALGADO ; Artur Bibiano de MELO FILHO ; Samara Alvachian C. ANDRADE² ; \\ Giselle Rabelo MACIEL ; ; Alda Verônica Souza LIVERA; Nonete Barbosa GUERRA
}

\section{RESUMO}

Considerando a importância das propriedades funcionais do amido resistente para a saúde, o elevado consumo de feijão macassar no Nordeste brasileiro e os efeitos do processo térmico e da estocagem sobre a estrutura do amido, foi realizado este trabalho com o objetivo de avaliar a influência de diferentes tratamentos hidrotérmicos (cocção sob pressão e sem pressão) e do armazenamento a $20^{\circ} \mathrm{C}$ por 15 e 30 dias, sobre a formação de amido resistente do feijão macassar em dois estádios de maturação (verde e seco). Para analisar os fatores combinados foi realizado um planejamento fatorial do tipo 2 com três variáveis independentes (fatores) e uma variável dependente (resposta). Todas as variáveis exerceram efeitos significativos na produção de AR e a maior formação foi registrada para o feijão seco devido à hidratação prévia a cocção sem pressão, além do tempo de armazenamento congelado de 30 dias. No que diz respeito às analises fisicas, após os tratamentos hidrotérmicos, ocorreram transformações nos padrões de cristalinidade e no aspecto morfológico dos feijões.

Palavras-chave: amido resistente; processamento térmico; feijão macassar.

\section{SUMMARY}

MODIFICATION OF THE CONCENTRATION OF RESISTANT STARCH IN MACASSAR BEAN (Vigna unguiculata L. WALP) HYDROTHERMAL PROCESS AND FREEZING. Considering the importance of the functional properties of resistant starch for health, the high consumption of the macassar bean in the northeast of Brazil and the effects of the thermal process and storage on the structure of the starch, this work was implemented to evaluate the influence of different hydrothermal treatments (cooking under pressure and whithout pressure) and of storage at $20^{\circ} \mathrm{C}$ for 15 and 30 days, on the formation of resistant starch in the macassar bean, in two stages of maturation (green and dryed). To analyse the combined factors, a factorial design type 2 was realized with three independent variables (factors) and one dependent variable (response). All the variables exercised significant effects on the production of the resistant starch and the highest formation was registered for the dried bean due to the previous hydration before cooking without pressure, as well as the 30 day frozen storage. Concerning the physics analysis after the hydrothermic treatments there are transformations in the cristalinity patterns and in the morphologic aspect of the beans.

Keywords: resistant starch; thermal processing; macassar bean.

\section{1 - INTRODUÇÃO}

Dos carboidratos que representam 40 a $80 \%$ do valor energético total da alimentação diária [8], o amido é o principal componente e, conseqüentemente a maior fonte de glicose da dieta humana, além do relevante papel exercido no que diz respeito às alterações metabólicas como diabetes, obesidade e ao desenvolvimento de doenças coronarianas.

O interesse atual em estudar os efeitos biológicos dos carboidratos baseia-se na suposição de que aproximadamente $10 \%$ do amido ingerido é resistente à hidrólise que ocorre no trato digestivo, e como tal é fermentado no cólon onde exerce um efeito similar ao da fração solúvel da fibra, motivo pelo qual este amido resistente (AR), é considerado um dos componentes da fibra alimentar $[8,11,18,29]$.

Pesquisas de VONK et al. [30] e BEDNAR et al. [3], dentre outras, têm demonstrado a participação do amido

Recebido para publicação em 22/05/2003. Aceito para publicação em 18/05/2005(001135).

Laboratório de Experimentação e Análise de Alimentos - LEAAL Departamento de Nutrição, Universidade Federal de Pernambuco. Avenida Prof. Moraes Rêgo s/n. Cidade Universitária. CEP: 50670001, Recife-PE.E-mail: silvanasalgado@ufpe.br

A quem a correspondência deve ser enviada. resistente no processo fermentativo no cólon por certas bactérias probióticas, como as bífidobactérias, que promovem o desenvolvimento de uma população bacteriana saudável, em detrimento de espécies bacterianas mais perigosas com conseqüentes beneficios para a saúde humana.

Considerando que, grande parte do amido consumido na dieta do brasileiro é proveniente das leguminosas; que o conteúdo de AR nos alimentos é variável e dependente das características físico-químicas do grânulo de amido, bem como dos processos térmicos e das condições de estocagem aos quais foram submetidos; e que a prática de congelamento, utilizada para prolongar a vida útil dos alimentos, pode provocar alterações na estrutura do grânulo do amido, favorecendo a formação de amido resistente [19], foi realizado este trabalho com o objetivo de avaliar os efeitos de distintos tratamentos térmicos e tempos de armazenamento congelado sobre a concentração de AR em feijão macassar verde e seco.

\section{2 - MATERIAL E MÉTODOS}

\section{1 - Material}

Foi constituído pelo feijão macassar (Vigna unguiculata L. Walp) nos estádios de maturação verde e seco, adquiridos de forma aleatória no comércio local da Região Metropolitana do Recife. 


\section{2 -Métodos}

\subsection{1 - Delineamento experimental}

Para analisar os efeitos combinados dos estádios de maturação dos feijões, tipos de cocção e tempo de armazenamento sobre a formação de AR foi realizado um planejamento fatorial do tipo $2^{3}$ [2], com três variáveis independentes (fatores) e uma variável dependente (resposta) totalizando 8 ensaios, com cinco repetições cada, cujas condições (níveis codificados e decodificados) encontram-se na Tabela 1.

TABELA 1 - Codificação do delineamento experimental

\begin{tabular}{cccc}
\hline Ensaio & Grau de maturação & Tipo de cocção & $\begin{array}{c}\text { Tempo de } \\
\text { armazenamento }\end{array}$ \\
\hline 1 & -1 & -1 & -1 \\
2 & 1 & -1 & -1 \\
3 & -1 & 1 & -1 \\
4 & 1 & 1 & -1 \\
5 & -1 & -1 & 1 \\
6 & 1 & -1 & 1 \\
7 & -1 & 1 & 1 \\
8 & 1 & 1 & 1 \\
\hline
\end{tabular}

Nota: maturação: -1 (seco) e 1 (verde); tempo de armazenamento: -1 (30 dias) e 1 (15 dias); tipo de cocção: -1 (sob pressão) e 1 (sem pressão).

\subsection{2 - Tratamento hidrotérmico}

Os feijões foram selecionados, tendo em vista a eliminação dos grãos defeituosos lavados, em água corrente e submetidos aos seguintes processos de cocção:

- Cocção sem pressão: utilizou-se $5 \mathrm{~mL}$ de água/g do grão até o completo cozimento.

- Cocção sob pressão (1kgf/cm² ) em $5 \mathrm{~mL}$ de água/g de grão, durante 30 e 15 minutos para os grãos secos e verdes, respectivamente.

No caso dos grãos secos, foram precedidos de hidratação por 8 horas em água potável. Após a cocção dos grãos verdes e secos, a água foi drenada e os grãos foram armazenados sob congelamento $\left(-20^{\circ} \mathrm{C} \pm 1\right)$ por 15 e 30 dias. Ao final destes periodos, amostras de cada ensaio foram retiradas do congelador e secadas em estufa ventilada a $45^{\circ} \mathrm{C}$ durante 18 horas, e em seguida trituradas em multiprocessador, pulverizadas até obter uma granulometria $<0,250 \mathrm{~nm}$.

\subsection{3 - Métodos químicos e físicos}

Para avaliar as modificações químicas e físicas decorrentes do processamento, os grânulos de amido foram isolados de acordo com ROSIN, LAJOLO \& MENEZES [22], cujo princípio baseia-se na remoção das proteínas da amostra com solução tampão seguido da decantação do amido por centrifugação. Os grânulos foram submetidos às análises descritas a seguir.

- Difração de raio-X: em Difratômetro Siemens D500 com radiação CuKa a 40KV 40mA, sendo a velocidade de varredura de 2,5 segundos, sob ângulo $2 \theta$ variando de $5-4^{\circ}$, utilizando o padrão JCPDSInternacional Centre for Diffraction 2000.

- Microscopia eletrônica de varredura (MEV): em microscópio eletrônico de varredura (MEV) JEOL modelo JMS 5900 sob aceleração de $15 \mathrm{KV}$ a $1000 \mathrm{X}$ e 1600X.

- Amido resistente, segundo FAISANT et al. [7]: fundamenta-se no uso de enzimas para degradar a fração de amido resistente, e este, é quantificado por meio da glicose liberada pelo método glicose-oxidase.

\section{3 - Análise dos resultados}

O teor de amido resistente para todos os ensaios foi avaliado utilizando o programa Statistica, versão 6.0 Windows.

\section{3 - RESULTADOS E DISCUSSÃo}

\section{1 - Teor de amido resistente}

Os teores de AR nas amostras de feijão verde e seco, submetidos a diferentes tipos de cocção e tempo de armazenamento, estão descritos na Tabela 2.

TABELA 2 - Variação do teor de AR em feijão macassar cozido (base seca) em função das variáveis: maturação do grão, tipo de cocção e tempo de armazenamento

\begin{tabular}{|c|c|c|c|}
\hline & ENSAIO & $\mathrm{X} \pm \mathrm{DP}$ & $\mathrm{CV}$ \\
\hline $1-$ & Grão seco, cozido sob pressão, armazenado por 30 dias & $4,48 \pm 0,40$ & $8,92 \%$ \\
\hline $2-$ & Grão verde, cozido sob pressão, armazenado por 30 dias & $2,24 \pm 0,05$ & $2,23 \%$ \\
\hline $3-$ & Grão seco, cozido sem pressão, armazenado por 30 dias & $4,63 \pm 0,43$ & $9,30 \%$ \\
\hline 4- & Grão verde, cozido sem pressão, armazenado por 30 dias & $3,15 \pm 0,22$ & $6,90 \%$ \\
\hline $5-$ & Grão seco, cozido sob pressão, armazenado por 15 dias & $1,64 \pm 0,22$ & $13,41 \%$ \\
\hline 6- & Grão verde, cozido sob pressão, armazenado por 15 dias & $1,56 \pm 0,24$ & $15,38 \%$ \\
\hline 7- & Grão seco, cozido sem pressão, armazenado por 15 dias & $2,56 \pm 0,23$ & $8,98 \%$ \\
\hline 8- & Grão verde, cozido sem pressão, armazenado por 15 dias & $1,41 \pm 0,19$ & $13,47 \%$ \\
\hline
\end{tabular}

Pelas respostas obtidas, as combinações empregadas nos ensaios 1 e 3 resultaram nos maiores teores de $\mathrm{AR}, 4,48$ e 4,63g\%, respectivamente. Os estudos realizados por POMERANZ [19]; HOBLER et al. [12]; SAGUN \& ARCOT [23]; KUTOS et al. [14], sugerem que o teor de amido resistente encontra-se relacionado a gelatinização e retrogradação, embora, seu teor nos alimentos, dependa do tipo de processamento, relação amilose/amilopectina, tempo e temperatura de armazenamento e quantidade de água empregada no processamento que atua como agente plastificante.

Por meio da análise estatística dos dados, constatase que os fatores independentes utilizados nesta pesquisa exerceram influência sobre o percentual de AR, principalmente a maturação e tempo de armazenamento ( $T a-$ bela 3). No que se refere às interações, a Tabela 3 de- 
monstra que as combinações maturação x cocção e cocção x armazenamento, não exerceram efeito significativo sobre o teor de AR.

Embora estatisticamente significante, o efeito da cocção sob pressão no teor de AR não atingiu resultados semelhantes aos de SKARABANJA \& KREFT [26]; NAMRATHA, ASNA \& PRASAD [17] que encontraram valores de AR em vegetais indianos na ordem de $0,35 \mathrm{~g} \%$ a $5,78 \mathrm{~g} \%$; RANHOTRA, GELROTH \& EISENBRAUN [20]. A cocção sobre alta pressão $\left(1 \mathrm{kgf} / \mathrm{cm}^{2}\right)$ ao provocar uma ruptura gradual de algumas ligações glicosídicas do amido, origina produtos capazes de formar agregados mais complexos com a amilose retrogradada e/ou complexos amilose-lipídio, contribuindo portanto, para a formação de amido resistente. $\mathrm{O}$ diferenciado registro nesta pesquisa (Figura 1) pode ter sido decorrente da quantidade de água utilizada, pois, segundo COLONNA, LELOUP \& BULEON [5] a produção de AR é máxima sob pressão em condições de baixa umidade (1 amido: 3,5 água) . CHAMP \& FAISANT [4] também enfatizou o favorecimento da retrogradação a temperatura de estocagem a $4^{\circ} \mathrm{C}$ com hidratação superior a $70 \%$.

TABELA 3 - Determinação dos efeitos principais do planejamento fatorial 2

\begin{tabular}{lrl}
\hline \multicolumn{1}{c}{$\begin{array}{c}\text { Itens avaliados } \\
\text { (amostra cozida) }\end{array}$} & Amido resistente \\
\hline Fatores & Maturação (1) \\
Cocção (2) & $-1,24^{*}$ \\
& Armazenamento (3) & $0,46^{*}$ \\
Interações & 1 e 2 & $-1,83^{*}$ \\
& 1 e 3 & $-0,077$ \\
2 e 3 & $0,62^{*}$ \\
*Efeitos significativos & 1,2 e 3 & $-0,074$ \\
& & $-0,46^{*}$ \\
\hline
\end{tabular}

Recentemente, NAMANTHA, ASNA \& PRASAD [17], ao avaliar a formação de AR nos alimentos, confirmaram o efeito do congelamento sobre a intensidade da retrogradação, explicando que nesta condição a organização do grânulo de amido segue a teoria da cinética da formação de cristais, cuja nucleação ocorre em temperatura bem abaixo da fusão dos mesmos $\left(150^{\circ} \mathrm{C}\right)$ e acima da transição vítrea $-5^{\circ} \mathrm{C},-10^{\circ} \mathrm{C}[6]$.

É necessário ressaltar que, mesmo sob congelamento, os teores de AR encontram-se relacionados segundo a origem botânica do amido, como relatado por MENEZES \& LAJOLO [16], LINTAS \& CAPELLONI [15] e SOUZA LEITE [25] para o feijão cozido e congelado (Phaseolus vulgaris), cujos valores de AR foram superiores (4,0 a $6,5 \mathrm{~g} \%$ ) aos obtidos neste trabalho.

O teor de AR, segundo GOÑI, GARCIA-ALONSO \& GARCIA [11], também depende dos ciclos de aquecimento sob calor úmido, no que foi ratificado por VELASCO, RASCON \& TOVAR [29] que encontrou 7,6\% de AR em fei-

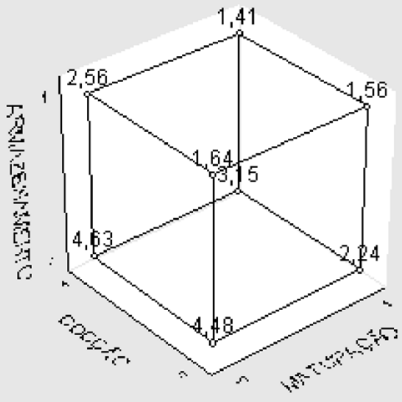

FIGURA 1 - Média do teor de AR em feijão macassar (base seca) obtido em função do tempo de armazenamento, tipo de cocção e grau de maturação do feijão

jão preto estocado e reaquecido. No que diz respeito à aplicação do calor seco em leguminosa esta foi descartada por KELKAR, SHASTRIP \& RAO [13], tendo em vista a formação de compostos de Maillard que podem ser quantificados como AR.

De acordo com a literatura, as leguminosas quando processadas aumenta o teor de AR, devido ao elevado teor de amilose [1]. POMERANZ [19] e HOEBLER et al. [12] encontraram correlação positiva entre este glicano e a formação de AR em pães, ervilha e batatas; fato também comprovado por SALGADO [24], trabalhando com o feijão macassar, que encontrou o triplo de amilose no grão maduro, em relação ao verde. Outras explicações plausiveis para a maior formação de AR nos grãos secos, segundo SALGADO [24], dizem respeito: à prática culinária de hidratar os grãos antes da cocção $[13,21]$ que concorre para o aumento do teor de AR; o elevado teor de açúcares presente no grão verde que pode diminuir a retrogradação do amido devido à formação de pontes entre o açúcar e as cadeias de amilose, estabilizando as regiões amorfas do grânulo $[1,23]$ e ao maior rompimento do cotilédone do grão no estádio de maturação verde. No grão seco, segundo TOVAR [28], as paredes celulares mantêm sua integridade diminuindo o acesso das enzimas amiloliticas ao amido, classificando-o em amido resistente tipo1 [8].

A contribuição do tempo de armazenamento congelado para aumentar o teor de AR, era esperada, em face de estrutura ramificada da amilopectina, cujo processo de retrogradação, por ser lento, necessita de um maior tempo de armazenamento conforme demonstrado na Figura 1, especialmente, para o feijão seco cozido. Trabalho implementado por SOUZA LEITE [25], sobre o teor de AR ( 4 a $6 \%$ base seca) em diferentes cultivares de feijões armazenados a $20^{\circ} \mathrm{C}$ durante 30 dias, confirma esta tendência.

\section{2 - Características físicas do grânulo de amido dos feijões processados com maior teor de ami- do resistente}

Segundo o detalhamento da morfologia, grânulos de amido in natura, independentemente do grau de matura- 
ção, apresentam-se riniformes e de tamanhos variáveis (Figura 2A). As alterações iniciadas com o tratamento hidrotérmico e consolidadas durante a estocagem sob congelamento, processo responsável pelas maiores transformações estruturais, podem ser visualizados na Figura $2 B$.

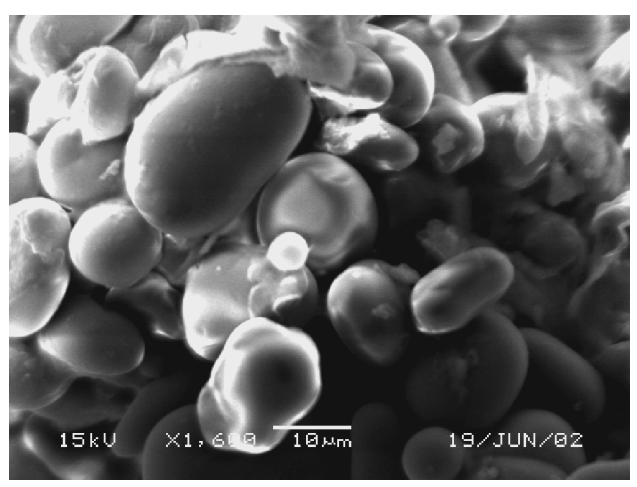

FIGURA 2A - Grânulos de amido in natura

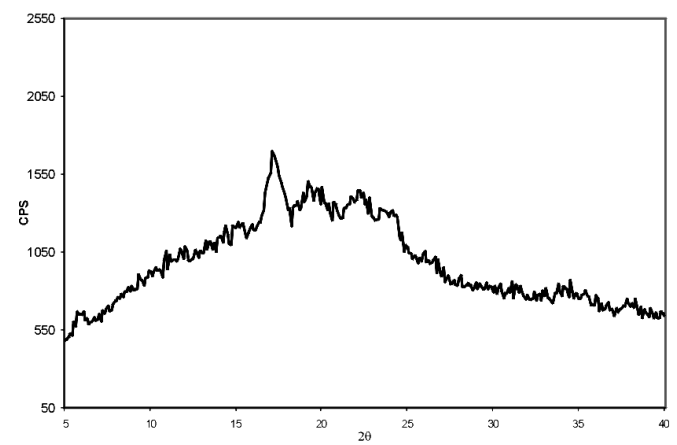

Processado Padrão B

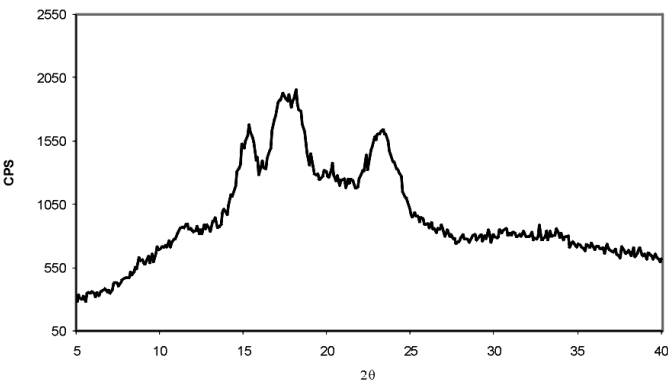

Verde Padrão C

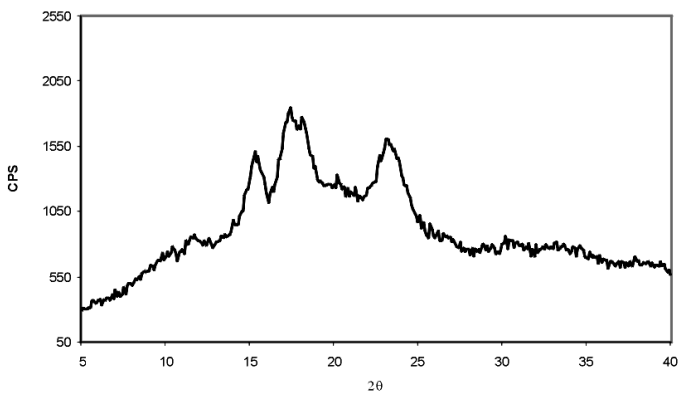

Seco Padrão A

FIGURA 3 - Difractograma de raio-X do amido de feijão macassar
Com relação à cristalinidade GALLANT, BOUCHET $\&$ BALDWIN [10] constataram que o amido nativo possui $15 \%$ a $45 \%$ de cristais, com padrão diferenciado quanto à organização tridimensional das estruturas. Por meio da difração de raio-X constatou-se que, o estádio de maturação influenciou o tipo do padrão de cristalinidade dos

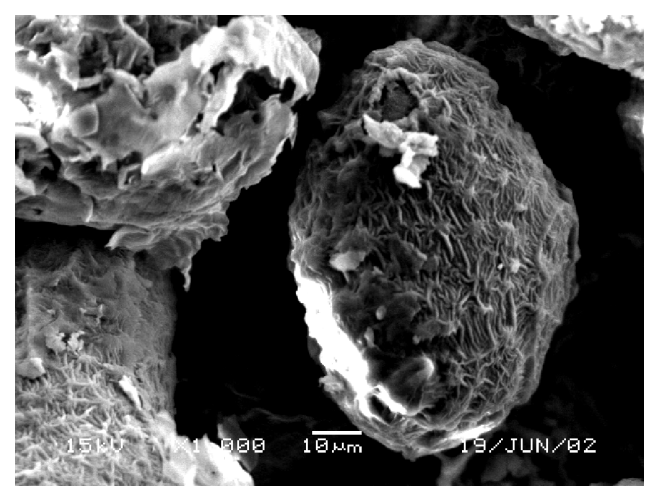

FIGURA 2B - Grânulos de amido processado

feijões em estudo (Figura 3). A análise dos difractogramas corresponde aos padrões do JCPDS-Internacional Centre for Diffraction 2000, onde se observa que o amido com padrão tipo B (feijão processado) apresenta um pico mais intenso na região de espaçamento em torno de 14 a 20 (20). Quanto aos padrões de amido A (feijão seco) e C (feijão verde), embora os difractogramas sejam visualmente próximos, o tipo $\mathrm{C}$ apresenta picos de maior intensidade de difração nas regiões de espaçamento próximas a 15 e $18(2 \theta)$.

Essas diferenças podem ser atribuídas as interações químicas e estrutura organizacional dos grânulos. O padrão tipo A possui a cadeia de amilopectina mais curta, a estrutura é ortogonal e contém apenas 8 moléculas de água com ligações pouco numerosas e irregulares, sendo a amilose distanciada da amilopectina por uma região amorfa, que é menos densa, absorve água mais rapidamente e é mais susceptível as modificações químicas e enzimáticas [8]. Com relação ao padrão C (feijão verde), observa-se maior intensidade do pico do difractograma sugerindo fortes ligações internas das moléculas e maior grau de associação entre as cadeias de amido.

Nos ensaios 3 e 4, cujo teor de AR foi superior aos demais, foi observada a estrutura cristalina dos grânulos de amido dos feijões, de modo a avaliar a influência do processo hidrotérmico. Verificou-se (Figura 3) uma alteração do padrão para $\mathrm{B}$, o que segundo GALLANT et al. [9], poderá ocorrer pela fusão dos cristalitos de amido, seguido de uma transformação estrutural durante a estocagem. Alterações para outros padrões podem ocorrer segundo TEIXEIRA et al. [27], que registraram em amido de milho, mudanças de A para C. Segundo este autor, estudos micrográficos demonstram que o tipo B tende a ser mais resistente a enzimas amilolíticas. Esta tendência é 
devida às cadeias longas e compactas de amilopectina de alta cristalinidade, reforçada por numerosas associações com moléculas menores e espiraladas de amilose, cuja estrutura hexagonal é formada por seis duplas hélices conectadas por pontes de hidrogênio. $\mathrm{O}$ tipo $\mathrm{C}$ também é resistente à $\alpha$-amilase pancreática [9] .

Do ponto de vista nutricional, o fenômeno da gelatinização, seguido da retrogradação nos tratamentos ocorrido nesta pesquisa, é considerado benéfico pois, aumenta o teor de fibra alimentar. O que justifica o foco de interesse por esta pequena fração é a necessidade de comprovar as propriedades funcionais a ela atribuída, especialmente àquelas relacionadas ao papel exercido pelos ácidos graxos de cadeia curta produzidos durante a fermentação colônica.

\section{4 - CONCLUSÕES}

- O tipo de cocção, o grau de maturação e o tempo de armazenamento exerceram significativos efeitos na produção de AR, isoladamente e através das interações.

- O processamento hidrotérmico alterou o aspecto morfológico original e o padrão de cristalinidade para o tipo B.

\section{5 - REFERÊNCIAS BIBLIOGRÁFICAS}

[1] ANNISON, G.; TOPPING, D.L. Nutritional role of resistant starch: chemical, structure vs physiological function. Annual Review Nutrition, v. 14, p. 297 320,1994.

[2] BARROS NETO, B.; SCARMINIO, I.S.; BRUNS, R.E. Planejamento e Otimização de Experimentos. Editora UNICAMP. 2 edição, 299p, 1995.

[3] BEDNAR, G.E.; PATIL, A . R.; MURRAY, S. M.; GRIESHOP, C.M.; MERCHEN, N. R.; FAMEY Jr, G.C. Starch and fiber fractions in selected foods and feed ingredients affect their small intestinal digestibility and fermentability and their large bowel fermentability in vitro in a canine model. Journal of Nutrition, v. 131, n.2, p.276-286, 2001.

[4] CHAMP, M.; FAISANT, N. Resistant Satarch. In: Carbohydrates as Organic Raw Materials II. Van Bekkum M.; Roper, M.; Meragen, F. p.189-215,1994.

[5] COLONNA, P.; LELOUP, V.; BULÉON, A. Limiting factors of starch hydrolysis. European Journal Clinical Nutrition, v.46, s.2, p. S17-S32, 1992.

[6] ESCARPA, A.; GONZÁLEZ, M.C. Tecnologia del almidón resistente. Food Science and Technology International, v.3, p.149-161, 1997.

[7] FAISANT, N.; PLANCHOT, V.; KORLOWSKI, F.; PACOURET, M.P.; COLONNA, P.; CHAM, M. Resistant starch determination adapted to products containing high level of resistant starch. Science des Aliments, v.15, p. 83-89, 1995.

[8] FREITAS, M. C. J. Amido resistente: propriedades funcionais. Nutrição Brasil, v. 1, p. 40-48,2002.

[9] GALlANT, D.J.; BOUCHET, B.; BULÉON, A.; PÉREZ, S. Physical characteristics of starch granules and susceptibility to enzymatic degradation. European Journal of Clinical Nutrition, v.46, p.3-165, 1992.

[10] GALLANT, D.J.; BOUCHET, B.; BALDWIN, P.M. Microscopy of starch: evidence of a new level of granule organization. Carbohydrate Polymers, v.32, p.177-191, 1997.

[11] GOÑI, I.; GARCIAALONSO, A.; GARCIA, D. Almidón resistent componente indigestible de la dieta alimentaria. Alimentaria, n.26, p.31-33,1995.

[12] HOEBLER, C.; KARINTHI, A.; CHIRON, H.; CHAMP, M.; BARRY, J. L. Biovailability of starch in bread rich in amylose. Metabolic responses in healthy subjects and starch structure. European Journal Clinical Nutrition, v.53, p.360-366, 1999.

[13] KELKAR, M.; SHASTRI, P.; RAO, B.Y. Effect of processing on in vitro carbohydrate digestibility of cereals and legumes. Journal Food Science Technology, v.33, n. 6, p.4932-4937, 1996.

[14] KUTOS, T.; GOlOB, T.; KAC, M.; PlestenJaK, A. Dietary fiber content of dry and processed beans. Food Chemistry, v.80, n.3, p.231-235, 2003.

[15] LINTAS, C.; CAPPELONI, M. Effect of processing on legume resistant starch. European Journal of Clinical Nutrition, v.46, n.2, p.S101 S104, 1992.

[16] MENEZES, E.W.; LAJOLO, F.M. Contenido em Fibra dietética y Almidón Resistente em Alimentos y Productos Iberoamericanos. Conselho Nacional de Desenvolvimento Cientifico e Tecnológico. São Paulo, 121 p.,2000.

[17] NAMRATHA, J.; ASNA, U.; PRASAD, N.N. Effect of storage on resistant starch content of processed ready-to eat foods. Food Chemistry, v.79, n.3, p.395-400, 2002.

[18] OSORIODÍAZ, P.; BELLOPÉREZ, L. A.; AGAMAACEVEDO, E.; VARGASTORRES, A.; TOVAR, J.; LÓPEZ, P. O. In vitro digestibility and resistant starch content of some industrialized commercial beans (Phaseolus vulgaris L.). Food Chemistry, v. 78, p.333-337, 2002.

[19] POMERANZ, Y. Research and development regarding enzyme resistant starch (RS) in the USA: a review. European Journal of Clinical Nutrition, v.46, Sppl 2, p. S63 S68, 1992.

[20] RANHOTRA, G.S.; GELROTH, J.A.; EISENBRAUN, G.J. High fiber white flour and its use in cookie products. Cereal Chemistry, v.68, n.4, p.432-434, 1991.

[21] REHMAN, ZIAUR.; SALARIYA, A . M.; ZAFAR, S. I. Effect of processing on available carbohydrate content and starch digestibility of Kidney beans (Phaseolus vulgaris L.). Food Chemistry, v.73, p.351-355, 2001.

[22] ROSIN, P.M.; LAJOLO, F.M.; MENEZES, E.W. Measurement and caracterization of dietary starches. Journal of Food Composition and Analysis . v. 14., n.4., p.367-377, 2002.

[23] SAGUM, R. \& ARCOT, J. Effect of processing methods on the starch, nonstarch polysaccharides and in vitro starch and protein digestibility three varieties of rice with varying levels of amylose. Food Chemistry, v. 70,n.1, p.107-111, 2000.

[24] SALGADO, S.M. Efeito do processo hidrotérmico sobre o amido do feijão macassar (Vigna unguiculata L.) e 
suas respostas fisiológicas. 2003, 77p. Tese Doutorado. Departamento de Nutrição. Universidade Federal de Pernambuco.

[25] SOUZA LEITE, M. Caracterização do amido e formação de amido resistente em diferentes cultivares de feijão (Phaseolus vulgaris L.). 1999, 67p. Tese Mestrado. Faculdade Ciências Farmacêuticas. Universidade de São Paulo.

[26] SKRABANJA, V.; KREFT, I. Resistant starch formation following autoclaving of buckwheat (Fagopyrum esculentum Moench) groats. An in vitro study. Journal Agricultural Food Chemistry, v.46, p.2020-2023, 1998.

[27] TEIXEIRA, M. A. V.; CIACCO, C.F.; TAVARES, D.Q.; BONEZZI, A. N. Ocorrência e Caracterização do amido resistente em amidos de milho e de banana. Ciênc. Tecnol. Aliment., v.18, n.2, 1998.

[28] TOVAR, J. Bioavailability of carbohydrates in legumes: digestible and indigestible fraction. Archivos latinoamericanos de Nutrición, v.44, n.4,p.3640, 1994 .

[29] VALASCO, Z.I.; RASCÓN, A ; TOVAR, J. Enzymic availabity of starch in cooked black beans (Phaseolus vulgaris L.) and cowpeas (Vigna sp.) Journal Agricultural Chemistry, v.43, p.1548 1551, 1997.

[30] VONK, R.J.; HAGEDOORN, R.E.; GRAAFF, R.; ELZINGA, H.; TABAK, S.; YANG, YUE-XIN.; STELLAARD, F. Digestion of so-called resistant starch sources in the human small intestine. American Journal of Clinical Nutrition, v. 72 , p. 432-438, 2000. 